\title{
Pulmonary Function and Respiratory Health of Military Personnel Before Southwest Asia Deployment
}

\author{
Andrew J Skabelund MAJ USAF MC MD, Frederic A Rawlins III MAJ USAF MC DO, \\ Edward T McCann MAJ USAF MC MD, Joshua A Lospinoso PhD, Lorraine Burroughs RRT, \\ Roger A Gallup MD, and Michael J Morris MD
}

\begin{abstract}
BACKGROUND: Significant concern exists regarding the respiratory health of military personnel deployed to Southwest Asia, given their exposures to numerous environmental hazards. Although the deployed military force is generally assumed to be fit, the pre-deployment respiratory health of these individuals is largely unknown. METHODS: Soldiers deploying to Southwest Asia were recruited from the pre-deployment processing center at Fort Hood, Texas. Participants completed a general and respiratory health questionnaire and performed baseline spirometry. RESULTS: One thousand six hundred ninety-three pre-deployment evaluations were completed. The average age of the participants was $32.2 \mathrm{y}$, and $\mathbf{8 3 . 1 \%}$ were male. More than one third of surveyed solders had a smoking history, $73 \%$ were overweight or obese, and $6.2 \%$ reported a history of asthma. Abnormal spirometry was found in $22.3 \%$ of participants. Soldiers with abnormal spirometry reported more asthma $(10.1 \%$ vs $5.1 \%, P<.001)$, failed physical fitness tests $(9.0 \%$ vs $4.6 \%, P=.02)$, and respiratory symptoms $(32.8 \%$ vs $24.3 \%, P=.001)$. DISCUSSION: This is the first prospective pre-deployment evaluation of military personnel that delineates factors potentially associated with the development of pulmonary symptoms and/or disease. This study suggests that deploying soldiers are older, heavier, frequently smoke, and may have undiagnosed pre-deployment lung disease. Abnormal spirometry is common but may not represent underlying disease. Self-reported asthma, wheezing, and slower 2-mile run times were predictive of abnormal spirometry. CONCLUSIONS: Pre-deployment evaluation of military personnel identified numerous soldiers with active pulmonary symptoms and abnormal spirometry. When combined with questions regarding asthma history, wheezing and exercise intolerance, spirometry may identify individuals at risk for deploymentrelated respiratory complaints. Key words: deployment; military personnel; asthma; spirometry. [Respir Care 2017;62(9):1148-1155. (C) 2017 Daedalus Enterprises]
\end{abstract}

\section{Introduction}

A debate exists regarding the effect of deployment on the respiratory health of military personnel who deploy to

Drs Skabelund, McCann, Lospinoso, and Morris are affiliated with the Pulmonary/Critical Care Service, Department of Medicine, San Antonio Military Medical Center, Fort Sam Houston, Texas. Dr Rawlins is affiliated with the Pulmonary/Critical Care Service, Keesler Medical Center, Keesler Air Force Base, Biloxi, Mississippi. Ms Burroughs is affiliated with Meridian Health Care, Rockdale, Texas. Dr Gallup is affiliated with Seton Medical Center, Harker Heights, Texas.

The authors have disclosed no conflicts of interest. The opinions in this work do not constitute endorsement by San Antonio Military Medical Center, the United States Army Medical Department, the United States
Southwest Asia supporting Operations Iraqi Freedom/Enduring Freedom/New Dawn. ${ }^{1}$ Deployed individuals may

\footnotetext{
Army Office of the Surgeon General, the Department of the Army, the Department of the Air Force, or the United States Government of the information contained therein.

Supplementary material related to this paper is available at http:// www.rcjournal.com.

Correspondence: Andrew J Skabelund Maj USAF MC MD, Pulmonary Disease Service (MCHE-ZDM-P), San Antonio Military Medical Center, 3551 Roger Brooke Drive, JBSA-Fort Sam Houston, TX 78234. E-mail: ajskabelund@gmail.com.
}

DOI: $10.4187 /$ respcare. 05438 
be exposed to significant levels of airborne particulate matter from geological dusts, burn pit emissions, wasted munitions, or even sulfur mine fires and chemical weapons caches. ${ }^{2}$ Evidence for a causative association between these exposures and the development of pulmonary disease, such as asthma, has been conflicting. ${ }^{3-5}$ The Armed Forces Health Surveillance Center concluded, based on limited evidence, that exposures to burn pit smoke did not appear to increase the risk for pulmonary complications. ${ }^{6}$ In 2011, the Institute of Medicine expressed concern specifically about burn pit particulate matter exposures but conceded that there was inadequate evidence to link these exposures to respiratory disease. ${ }^{7}$

A surge in respiratory complaints was observed following deployments to the first Gulf War (1990-1991) specifically related to burning oil fires. ${ }^{8}$ A survey of 1,560 veterans exposed to oil fire and dust storms reported increased respiratory symptoms, asthma, and chronic bronchitis, but longitudinal follow-up revealed no pulmonary function deterioration or permanent pulmonary sequelae. ${ }^{9}$ Studies from the recent Southwest Asian conflicts (2001 to the present) demonstrate similar increases in deploymentrelated respiratory complaints. ${ }^{10}$ The Millennium Cohort Study showed that previously deployed individuals had more respiratory complaints than never-deployed personnel (14\% vs $10 \%) .{ }^{11}$ A retrospective survey of 1,200 deployed soldiers also revealed that pulmonary symptoms were more common during deployment. ${ }^{12}$

These studies confirm an increased prevalence of deployment-related respiratory complaints, yet uncertainty remains regarding specific clinical diagnoses following deployments to Southwest Asia. Many studies lack spirometry data, fail to assess pre-deployment symptoms and functional status, and are biased by a retrospective estimation of pre-deployment respiratory health. The lack of baseline pulmonary function test (PFT) data has made it difficult to determine to what extent new-onset pulmonary disease can be attributed to Southwest Asia exposures. The dialogue is further confused by assertions that the fighting force is younger, healthier, and in better condition than the general population. ${ }^{12}$ Authors have also claimed that virtually no United States military personnel have asthma ${ }^{13}$ and all personnel passed their 2-mile run test before deployment. ${ }^{14}$ Furthermore, many studies are based upon soldiers' self-reported symptoms and diagnoses, but it is uncertain how reliable these diagnoses are. Approximately $5 \%$ of deploying soldiers report a history of asthma, but how this diagnosis was established is unclear. ${ }^{15}$

A 2010 Department of Defense/Veterans Affairs working group convened to investigate post-deployment lung disease. ${ }^{16}$ Recommendations included a pulmonary evaluation for individuals with chronic symptoms, abnormal PFTs, or reduced exercise tolerance. Pre- and post-deployment spirometry for all service members was also recom-

\section{QUICK LOOK}

\section{Current knowledge}

Military service members deployed to Southwest Asia complain of increased respiratory symptoms both during and following their time in these deployed locations. Several studies note an increased prevalence in asthma and other respiratory disorders following deployments to Southwest Asia, but these studies did not account for the pulmonary function and respiratory health of the service members before the deployment. To date, no study has examined the pulmonary health of armed service members before deployments to Southwest Asia.

\section{What this paper contributes to our knowledge}

Many deploying military members had abnormal spirometry and experienced respiratory complaints before traveling to Southwest Asia. The deploying service members were also older and heavier, and used tobacco more frequently than commonly believed. Abnormal spirometry was more likely in service members with a reported history of asthma, subjective wheezing, and failed fitness tests.

mended to objectively assess deployment-related respiratory changes. However, Department of Defense representatives advocated conducting a clinical study before universal implementation of pre-deployment spirometry. ${ }^{17}$ This study was designed to establish baseline PFTs, symptoms, and characteristics of military personnel before deployment with subsequent post-deployment follow up.

\section{Methods}

A prospective study was conducted involving military members preparing for deployment to Southwest Asia (Iraq, Afghanistan, Kuwait, or Qatar) from 2011 to 2014. All participants were recruited from Fort Hood, Texas during their centralized pre-deployment processing. Any soldier deploying to Southwest Asia was eligible for study participation; there were no specified exclusion criteria. The Brooke Army Medical Center institutional review board approved study design and implementation; all participants completed a written informed consent process.

Before deployment, all participants completed a questionnaire and underwent baseline spirometry. A similar post-deployment evaluation was conducted. The results of the post-deployment evaluations will be reported elsewhere. The pre-deployment questionnaire collected basic demographic, smoking, and previous deployment data. The par- 


\section{Pulmonary Function in Military Personnel}

ticipants reported their current medications, medical history, and pulmonary symptoms (dyspnea, cough, wheezing, sputum production, and exercise intolerance) over the previous month. Soldiers reported their 2-mile run times and whether they passed or failed their most recent Army Physical Fitness Test. The questionnaire is available (see the supplementary materials at http://www.rcjournal.com).

Participants performed baseline spirometry using a VMax spirometer (CareFusion, San Diego, California). They underwent a standard forced expiratory maneuver from maximal inhalation to maximal exhalation to record the $\mathrm{FEV}_{1}$ and $\mathrm{FVC}$ in accordance with American Thoracic Society standards for spirometry quality and reproducibility. No post-bronchodilator assessments were obtained.

Abnormal spirometry was defined as an $\mathrm{FEV}_{1}, \mathrm{FVC}$, mid-expiratory flow $\left(\mathrm{FEF}_{25-75 \%}\right)$, or $\mathrm{FEV}_{1} / \mathrm{FVC}$ below the lower limit of normal as defined by the National Health and Nutrition Examination Survey III reference values. ${ }^{18}$ Supranormal spirometry was defined as an $\mathrm{FEV}_{1}$ or FVC $>110 \%$ predicted. ${ }^{19}$

The estimated sample size for an adequate analysis of pre- and post-deployment data was 1,050 participants. This size was estimated for an $\alpha$ level of 0.05 and power level of 0.90 . Given a projected attrition rate of $40 \%$ (those lost to follow-up after deployment or those withdrawing consent), a target sample of approximately 1,750 participants was projected. The study was closed when the deployment tempo decreased and 1,698 soldiers had been enrolled.

Statistical analysis was performed to identify differences between subgroups. Subgroups such as those with and without previous deployments or those with and without spirometry abnormalities were analyzed. A 2-tailed, Fisher exact test was performed to identify statistical differences between the subgroups. To further explain the factors associated with abnormal spirometry, we conducted a logistic regression where abnormal spirometry was the response variable and the following factors were considered explanatory terms: number of deployments; smoker status (including pack-years); age; sex; race; run time; prescriptions; diagnoses for asthma, pneumonia, and other lung disease; and complaints of shortness of breath, wheezing, coughing, sputum, and decreased exercise tolerance. The model was fit by maximum likelihood estimation, and Wald tests for statistical significance were conducted for each of the resulting coefficients. Analysis was completed using RStudio Team (2015) (RStudio: Integrated Development for R, RStudio, Boston, Massachusetts).

\section{Results}

Data from 1,698 participants were collected before Southwest Asia deployments. Five participants withdrew consent, leaving a final cohort of 1,693 with pre-deployment evaluations. Baseline demographics of the cohort are
Table 1. Baseline Demographics

\begin{tabular}{lc}
\hline \hline \multicolumn{1}{c}{ Characteristics } & Values \\
\hline Age, mean \pm SD y & $32.2 \pm 9.1$ \\
Sex, $n(\%)$ & \\
Male & $1,407(83)$ \\
Female & $286(17)$ \\
Race, $n(\%)$ & \\
African-American & $343(20.2)$ \\
Asian & $76(4.5)$ \\
Caucasian & $979(57.8)$ \\
Hispanic & $295(17.4)$ \\
Body mass index, $n(\%)$ & \\
$\quad<25.0 \mathrm{~kg} / \mathrm{m}^{2}$ & $451(26.6)$ \\
$25.0-29.9 \mathrm{~kg} / \mathrm{m}^{2}$ & $904(53.4)$ \\
$\geq 30.0 \mathrm{~kg} / \mathrm{m}^{2}$ & $338(20.0)$ \\
Deployments, $n(\%)$ & \\
Never & $807(47.7)$ \\
Once & $463(27.4)$ \\
Two or more & $410(24.2)$ \\
Smoking, $n(\%)$ & \\
Never & $1,106(65.3)$ \\
Former & $327(19.3)$ \\
Current & $253(14.9)$ \\
Duty status, $n(\%)$ & \\
Active duty & \\
National Guard & \\
Reservist & \\
Most recent APFT, $n(\%)$ & $406(41.7)$ \\
Passed & $516(25.3)$ \\
Failed & \\
Profile/no running test & \\
\hline APFT $=$ Army physical fitness test & \\
\hline & \\
\hline & \\
\hline
\end{tabular}

shown in Table 1. Most participants were male and white, had previous Southwest Asia deployments, and were an average age of $32.2 \mathrm{y}$. More than one third of participants were current or former smokers, and $73 \%$ of the soldiers were overweight or obese. Only $5.6 \%$ reported fitness test 2-mile run failures, but nearly $12 \%$ had physically limiting conditions that exempted them from running or forced them to do an alternative walk test. Table 2 shows the type and frequency of pre-deployment pulmonary symptoms. Over a quarter of the soldiers reported experiencing respiratory symptoms in the previous month, and $10 \%$ reported having symptoms at least twice a week.

Table 3 characterizes reported medical conditions and pulmonary/allergy medication use. Asthma was self-reported in $6.2 \%$ of the participants. Reported asthma patients reported more inhaled corticosteroid use (18.1\%) and twice the incidence of respiratory symptoms (49.5\%). Of the 105 subjects reporting a history of asthma, only 34 had documented spirometry, and only 16 of the subjects with spirometry had either a bronchoprovocation challenge 
Table 2. Reported Pulmonary Symptoms in Previous Month

\begin{tabular}{lc}
\hline \hline Symptoms and Frequency & $n(\%)$ \\
\hline Any symptom & \\
$\quad$ Any & $444(26.2)$ \\
$\geq 2 /$ week & $170(10.0)$ \\
Dyspnea & \\
$\quad$ Any & $206(12.2)$ \\
$\geq 2 /$ week & $54(3.2)$ \\
Wheezing & \\
Any & $112(6.6)$ \\
$\geq 2 /$ week & $27(1.6)$ \\
Cough & \\
Any & $343(20.3)$ \\
$\geq 2 /$ week & $110(6.5)$ \\
Sputum production & \\
Any & $128(7.6)$ \\
$\geq 2 /$ week & $44(2.6)$ \\
Decrease in exercise tolerance & \\
Any & $170(10.0)$ \\
$\geq 2 /$ week & $46(2.7)$ \\
\hline
\end{tabular}

Table 3. Reported Medications and Medical History

\begin{tabular}{lr}
\hline \hline \multicolumn{1}{c}{ Medications/Medical History } & $n(\%)$ \\
\hline Medications & \\
Inhaled corticosteroid & $15(0.9)$ \\
Short-acting or long-acting $\beta$ agonist & $22(1.3)$ \\
Inhaled corticosteroid/long-acting $\beta$ agonist & $11(0.6)$ \\
Nasal corticosteroid & $58(3.4)$ \\
Leukotriene antagonist & $20(1.2)$ \\
Antihistamine & $157(9.3)$ \\
Decongestant & $41(2.4)$ \\
Reported medical history & \\
Asthma & $105(6.2)$ \\
Pneumonia & $150(8.9)$ \\
Unspecified pulmonary disease & $38(2.2)$ \\
Allergic rhinitis & $49(2.9)$ \\
Gastroesophageal reflux disease & $90(5.3)$ \\
Hypertension & $70(4.1)$ \\
Thyroid disease & $22(1.3)$ \\
Traumatic brain injury & $31(1.8)$ \\
Post-traumatic stress disorder & $84(5.0)$ \\
Obstructive sleep apnea & $54(3.2)$ \\
\hline
\end{tabular}

test or a proven reversible obstruction to confirm the diagnosis of asthma. Only 34 of 105 had a documented asthma ICD-9 code.

Mean pre-deployment spirometry data are presented in Table 4. Supranormal values were identified in 245 studies (14.5\%). Abnormalities below the lower limit of normal were noted in 378 participants (22.3\%). When compared with participants with normal spirometry (see Table 5), soldiers with abnormal spirometry (below the lower limit of normal) reported more asthma (10.1\% vs $5.1 \%$, $P<.001)$, failed physical fitness $(9.0 \%$ vs $4.6 \%, P=$ $.002)$, and respiratory symptoms $(32.8 \%$ vs $24.3 \%$, $P<.001)$.

A logistic regression analysis with abnormal spirometry as the response variable was performed. The following variables did not have a statistically significant effect on abnormal spirometry results: number of deployments, smoking status (including packs per day), age, medications prescribed, pneumonia diagnosis, shortness of breath, coughing, sputum, or decreased exercise. All else being equal, males had a statistically significantly higher chance of abnormal spirometry (odds ratio $=2.62, P<.001$ ). Compared with Asians, African Americans and whites had lower probabilities of abnormal spirometry (odds ratios $=0.40$ and $0.60, P=.004$ and $P=.069$, respectively), whereas Hispanics did not have a statistically significant difference. Increased run times had a strong and statistically significant effect on increasing the probability of abnormal spirometry (odds ratio $=1.25$ per additional minute, $P<.001)$. An asthma diagnosis increased probability of abnormal spirometry (odds ratio $=1.74$, $P=.029)$, whereas increased body mass index decreased the probability (odds ratio $=0.93$ per unit, $P<.001$ ). Table 6 showcases the demographic, spirometric, and medical differences between soldiers with and without deployment experience. Previously deployed soldiers were older and heavier and used tobacco more frequently. They were more likely to be prescribed inhalers but did not report asthma more frequently. Respiratory symptoms and nonrespiratory medical conditions were significantly more common among those with previous deployments.

Obesity, smoking, and posttraumatic stress disorder were also analyzed in this cohort. Compared with normal-weight soldiers, obese participants more frequently failed their physical fitness test $(10.7 \%$ vs $2.9 \%, P<.001)$ and reported more reflux disease ( $8.9 \%$ vs $3.5 \%, P=.002)$, hypertension ( $8.6 \%$ vs $1.1 \%, P<.001)$, and posttraumatic stress disorder $(7.7 \%$ vs $3.8 \%, P=.01)$. Compared with never-smokers, active smokers reported more dyspnea (19.0\% vs $9.9 \%, P<.001)$, wheezing $(12.6 \%$ vs $5.4 \%$, $P<.001)$, cough $(31.6 \%$ vs $16.9 \%, P<.001)$, and sputum production $(14.6 \%$ vs $6.3 \%, P<.001)$ and decreased exercise tolerance $(17.0 \%$ vs $7.9 \%, P<.001)$.

Finally, soldiers with posttraumatic stress disorder had a disproportionally high incidence of respiratory symptoms compared with soldiers without posttraumatic stress disorder $(52.4 \%$ vs $24.9 \%, P<.001)$. Soldiers with posttraumatic stress disorder reported more daily/weekly symptoms $(31.0 \%$ vs $8.9 \%, P<.001)$ and were more likely to have used tobacco products $(45.3 \%$ vs $33.7 \%$, $P=.02)$. However, there was no increase in reported respiratory diagnoses in the soldiers with posttraumatic 


\section{Pulmonary Function in Military Personnel}

Table 4. Pulmonary Function Testing Results

\begin{tabular}{|c|c|c|c|}
\hline Parameters & Values & Abnormal Pulmonary Function Tests & $n(\%)$ \\
\hline Spirometry values, mean $\pm \mathrm{SD}$ & & Supranormal values & \\
\hline $\mathrm{FEV}_{1}, \%$ predicted & $94.8 \pm 12.7$ & FVC $>110 \%$ predicted & $190(11.2)$ \\
\hline FVC, $\%$ predicted & $95.5 \pm 11.9$ & $\mathrm{FEV}_{1}>110 \%$ predicted & $180(10.6)$ \\
\hline $\mathrm{FEV}_{1} / \mathrm{FVC}$ & $0.82 \pm 0.06$ & Values below lower limit of normal & \\
\hline \multirow{5}{*}{$\mathrm{FEF}_{25-75 \%}, \%$ predicted } & $96.6 \pm 25.9$ & $\mathrm{FEV}_{1}$ & $229(13.5)$ \\
\hline & & $\mathrm{FVC}$ & $215(12.7)$ \\
\hline & & $\mathrm{FEF}_{25-75 \%}$ & $136(8.0)$ \\
\hline & & $\mathrm{FEV}_{1}-\mathrm{FVC}$ & $140(8.3)$ \\
\hline & & Any value below lower limit of normal & $378(22.3)$ \\
\hline
\end{tabular}

$\mathrm{FEF}_{25-75 \%}=$ forced expiratory flow during the middle half of the FVC maneuver

Table 5. Demographic and Clinical Comparison in Participants With Normal Versus Abnormal Spirometry

\begin{tabular}{lccc}
\hline \hline \multicolumn{1}{c}{ Spirometry } & $\begin{array}{c}\text { Normal } \\
(n=1,315)\end{array}$ & $\begin{array}{c}\text { Abnormal } \\
(n=378)\end{array}$ & $P$ \\
\hline Age, mean \pm SD y & $32.2 \pm 9.0$ & $31.9 \pm 9.6$ & .60 \\
BMI, mean \pm SD y kg/m ${ }^{2}$ & $27.1 \pm 3.5$ & $26.8 \pm 3.6$ & .11 \\
Current smoker, $n(\%)$ & $184(14.0)$ & $69(18.3)$ & .049 \\
Reported medical history, $n(\%)$ & & & \\
Asthma & $67(5.1)$ & $38(10.1)$ & .001 \\
Allergic rhinitis & $41(3.1)$ & $8(2.1)$ & .38 \\
Gastroesophageal reflux disease & $72(5.5)$ & $18(4.8)$ & .69 \\
Post-traumatic stress disorder & $62(4.7)$ & $22(5.8)$ & .41 \\
Obstructive sleep apnea & $40(3.0)$ & $14(3.7)$ & .51 \\
Symptoms in past 4 weeks, $n(\%)$ & & & \\
Any symptoms & $320(24.3)$ & $124(32.8)$ & .001 \\
Weekly/Daily symptoms & $125(9.5)$ & $45(11.9)$ & .17 \\
Any dyspnea & $133(10.1)$ & $73(19.3)$ & $<.001$ \\
Weekly/daily dyspnea & $38(2.9)$ & $16(4.2)$ & .19 \\
Any wheezing & $67(5.1)$ & $45(11.9)$ & $<.001$ \\
Weekly/daily wheezing & $14(1.1)$ & $13(3.4)$ & $<.001$ \\
Any cough & $249(18.9)$ & $94(24.9)$ & .01 \\
Weekly/daily cough & $79(6.0)$ & $31(8.2)$ & .15 \\
Any low exercise tolerance & $115(8.7)$ & $55(14.6)$ & .002 \\
Weekly/daily low exercise tolerance & $33(2.5)$ & $13(3.4)$ & .36 \\
& & &
\end{tabular}

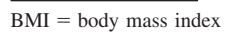

stress disorder. Associated data are available in the online supplementary materials.

\section{Discussion}

During the First Gulf War and the recent Southwest Asian conflicts, there have been unique airborne hazards, including oil well and sulfur mine fires, burn pits, chemical munitions, urban air pollution, and Southwest Asian geologic dusts. Neither the short- nor long-term effects on pulmonary health have been fully elucidated, but the po-
Table 6. Demographic and Clinical Comparison in Participants Based on Deployment History

\begin{tabular}{|c|c|c|c|}
\hline Characteristics & $\begin{array}{l}\text { Previously } \\
\text { Deployed } \\
(n=873)\end{array}$ & $\begin{array}{c}\text { Never } \\
\text { Deployed } \\
(n=807)\end{array}$ & $P$ \\
\hline Age, mean \pm SD y & $35.2 \pm 8.4$ & $28.9 \pm 8.7$ & $<.00$ \\
\hline $\mathrm{BMI}$, mean $\pm \mathrm{SD} \mathrm{kg} / \mathrm{m}^{2}$ & $27.7 \pm 3.4$ & $26.4 \pm 3.5$ & $<.00$ \\
\hline Male, $n(\%)$ & $758(86.8)$ & $637(78.9)$ & $<.001$ \\
\hline \multicolumn{4}{|l|}{ Smoking status, $n(\%)$} \\
\hline Never-smoker & $545(62.4)$ & $556(68.9)$ & .005 \\
\hline Former smoker & $194(22.2)$ & $128(15.9)$ & .001 \\
\hline Current smoker & $133(15.2)$ & $118(14.6)$ & .73 \\
\hline \multicolumn{4}{|l|}{ Spirometry, $n(\%)$} \\
\hline Supranormal PFT & $136(16.4)$ & $113(12.9)$ & .37 \\
\hline Any abnormality & $204(23.4)$ & $169(20.9)$ & .24 \\
\hline $\mathrm{FEV}_{1} / \mathrm{FVC}<$ lower limit of normal & $70(8.0)$ & $68(8.4)$ & .79 \\
\hline FVC $<$ lower limit of normal & $126(14.4)$ & $86(10.7)$ & .02 \\
\hline $\mathrm{FEV}_{1}<$ lower limit of normal & $127(14.5)$ & $99(12.3)$ & .17 \\
\hline $\mathrm{FEF}_{25-75 \%}<$ lower limit of normal & $70(8.0)$ & $65(8.1)$ & $>.99$ \\
\hline \multicolumn{4}{|l|}{ Reported medical history, $n(\%)$} \\
\hline Asthma & $61(7.0)$ & $43(5.3)$ & .18 \\
\hline Allergic rhinitis & $29(3.3)$ & $20(2.5)$ & .31 \\
\hline GERD & $65(7.4)$ & $24(3.0)$ & $<.001$ \\
\hline Hypertension & $51(5.8)$ & $19(2.4)$ & $<.001$ \\
\hline TBI & $28(3.2)$ & $3(0.4)$ & $<.001$ \\
\hline PTSD & $76(8.7)$ & $7(0.9)$ & $<.00$ \\
\hline OSA & $43(4.9)$ & $10(1.2)$ & $<.00$ \\
\hline \multicolumn{4}{|l|}{ Daily/weekly symptoms, $n(\%)$} \\
\hline Dyspnea & $45(5.2)$ & $9(1.1)$ & $<.001$ \\
\hline Wheezing & $21(2.4)$ & $6(0.7)$ & .01 \\
\hline Cough & $76(8.7)$ & $33(4.1)$ & $<.001$ \\
\hline Low exercise tolerance & $35(4.0)$ & $11(1.4)$ & $<.001$ \\
\hline
\end{tabular}

$\overline{\mathrm{BMI}}=$ body mass index

PFT $=$ pulmonary function test

$\mathrm{FEF}_{25-75 \%}=$ forced expiratory flow during the middle half of the FVC maneuver

GERD $=$ gastroesophageal reflux disease

$\mathrm{TBI}=$ traumatic brain injury

PTSD $=$ posttraumatic stress disorder

OSA $=$ obstructive sleep apnea 


\section{Pulmonary Function in Military Personnel}

tential detriment to lung function from airborne particulate matter remains. Understanding the underlying respiratory health of deploying military personnel may be critical in identifying potentially susceptible individuals with preexisting respiratory problems and pulmonary dysfunction. Specific interventions could be taken to assure these at risk individuals minimize their exposure to airborne environmental hazards.

This is the first prospective study of deploying military personnel designed to understand and delineate factors potentially associated with development of pulmonary disease in this population. A primary finding is that the current deploying force is older (mean age 32.2 y) and heavier (mean body mass index $27.1 \mathrm{~kg} / \mathrm{m}^{2}$ ) and may have underlying undiagnosed lung disease. Although many individuals reported asthma without a documented formal evaluation, a reported history of asthma was predictive of abnormal spirometry. Wheezing, a clinical surrogate for asthma in many population studies, also increased the odds of abnormal spirometry. Finally, every minute increase in the 2-mile run time increased the odds for abnormal spirometry.

This study is consistent with previous studies demonstrating increased respiratory symptoms in service members deployed to Southwest Asia. The data refute the assumption that all deploying service members are young, fit, and without respiratory symptoms. The study also shows that many deploying service members failed their fitness test or were unable to run 2 miles. Additionally, a sizeable proportion of the deploying force reported a history of asthma regardless of deployment history. Finally, these results correlate conditions such as posttraumatic stress disorder, smoking, and obesity with increased respiratory symptoms. Future studies should take pre-deployment pulmonary function, functional status, and comorbidities into account when analyzing the effect of deployment on the respiratory health of service members.

Deployment-related respiratory symptoms were reported as early as the First Gulf War. Army investigators examining the health effects of the 1991 Kuwaiti oil fires found increased upper-respiratory tract irritation, dyspnea, and cough associated with fire proximity. ${ }^{8}$ However, a cohort study of 1,560 veterans $5 \mathrm{y}$ after that conflict showed no correlation between self-reported asthma and bronchitis and modeled proximity to the oil fires. ${ }^{9}$ Additionally, $10 \mathrm{y}$ post-deployment, there were no PFT differences between a deployed and never-deployed cohort, suggesting no measurable effect from the reported exposures. ${ }^{20}$ The Millennium Cohort Study, an ongoing Naval Health Research Center survey evaluating the longitudinal health of military personnel, provides additional information. Baseline and follow-up surveys of 46,077 service members (10,753 deployed) found higher rates of newly reported respiratory symptoms in previously deployed compared with neverdeployed personnel (14\% vs 10\%). Similar rates of chronic bronchitis/emphysema (1\%) and asthma (1\%) were observed in both cohorts. ${ }^{11}$ Notably, short-term respiratory health effects due to specific exposures have not been identified. United States Army Public Health Command epidemiologic research at enhanced particulate matter surveillance sites found no association with increased particulate matter exposures (primarily geologic dusts) and cardiorespiratory events requiring medical encounters. ${ }^{21}$ The United States Army Public Health Command evaluated trends in rates of chronic lung diseases in the military population from 2001 through 2013. Over the 13-y study period, rates of asthma and chronic bronchitis steadily decreased, whereas an increase in nonspecific bronchitis drove an overall increase in chronic respiratory disease. ${ }^{22}$

Ongoing clinical studies are being conducted to characterize chronic respiratory diseases in the redeploying population but are generally limited by a lack of pre-deployment pulmonary data, including PFTs. In 2014, Department of Defense investigators prospectively evaluated 50 military members who reported new-onset dyspnea within 6 months of returning from deployment. Participants completed a standardized evaluation, including full PFTs, methacholine challenge, chest CT imaging, and fiberoptic bronchoscopy. Forty-two percent of subjects had normal findings, whereas another $40 \%$ had either asthma or evidence of increased airway hyperreactivity. ${ }^{3}$ Veterans Affairs investigators completed PFTs on 124 deployed veterans as part of a post-deployment evaluation. Longer deployments were associated with increased bronchodilator responsiveness with a trend toward increased air flow limitation ${ }^{23}$

Both asthma and airway hyperreactivity are common in military personnel with respiratory complaints. ${ }^{21}$ These conditions no longer automatically disqualify individuals from military service, and personnel may remain on active duty with well-controlled disease. Extreme Southwest Asian climate conditions, geologic dust, and burn pit smoke exposures may worsen asthma control and increase exacerbations. Roop et al ${ }^{15}$ surveyed deploying Army personnel and identified 5\% of troops with a pre-deployment diagnosis of asthma. Both asthma subjects and non-asthma subjects had increased respiratory symptoms during deployment; asthma subjects reported poor symptom control in theater. A single-center review of 6,000 Veterans Affairs medical records (ICD-9 diagnostic codes with minimal PFT data) noted higher rates of new-onset asthma in deployed personnel from 2004 to 2007 compared with never-deployed personnel (6.6\% vs $4.3 \%) .5$ The study did not address any asthma symptoms or related conditions that existed pre-deployment. Department of Defense investigators conducted an in-depth medical record review of 400 individuals diagnosed with asthma undergoing a medical fitness-for-duty evaluation. Asthma was confirmed with PFTs in only $78 \%$ of the subjects. Fifty percent had 


\section{Pulmonary Function in Military Personnel}

never deployed, 25\% were diagnosed pre-deployment, and $25 \%$ of the asthma subjects were diagnosed post-deployment. There were inadequate data to determine whether this was either undiagnosed preexisting disease aggravated by airborne exposures or new-onset disease in the postdeployment group. However, there were no differences in PFTs or asthma severity based on time of diagnosis or deployment history. ${ }^{24}$

A workshop at the 2011 Department of Defense/Veterans Affairs Airborne Hazards Conference addressed the adoption of screening spirometry in military personnel. Four issues were raised as potential barriers to implementation: cost, reliability, pre- and post-deployment spirometry, and use of spirometry to detect new pulmonary disease $^{25}$ The United States Army Public Health Command provided an in-depth analysis for a single spirometry examination and projected start-up costs to be nearly $\$ 35$ million. Primary issues in periodic spirometry evaluation are to establish good baseline measurement, maintain quality and within-person reproducibility, and identify individuals with excessive lung function decline. ${ }^{26}$ Currently, the Department of Defense electronic medical record cannot support tracking individual examinations to establish any trend. Furthermore, if the proportion who develop pulmonary disease is limited, as suggested by current epidemiologic data, there would be no benefit in obtaining baseline spirometry for the vast majority of military personnel who never develop pulmonary disease.

Finally, the workshop addressed limiting testing to preand post-deployment spirometry. Implementation of preand post-deployment spirometry would have significant logistic implications given the numbers $(>2.5$ million personnel deployed) and the numerous pre-deployment locations. The data in this study suggest possible value in implementing a pre-deployment screening questionnaire for respiratory symptoms and preexisting pulmonary disease. Those with positive responses could then undergo pre-deployment spirometry testing with repeat testing when returning. This approach may better identify personnel with demonstrable post-deployment PFT reductions due to underlying lung disease; however, many personnel may not honestly answer the questions due to a perception that it may prevent deployment or compensation for deploymentrelated lung disease.

This study had several weaknesses. First, the participants were all soldiers from a single centralized deployment center. Although this is a large single-center sample, the histories, medical conditions, and exposures may not fully represent the entire Army. Other bases and deployment centers may have soldiers with more intense exposures and worse lung function. Additionally, only the Army was represented in this cohort. The conditions endured during deployment of the Marine Corps may be like those of the Army, but the Air Force and Navy have distinct missions that will entail their own unique hazards.

Additionally, all participants had been deemed fit for deployment. It is possible that individuals with severe exposures and subsequent lung disease were unfit for deployment or had separated from the service, thus underestimating the effect of previous deployments on pulmonary function. Many of these questions should be answered with the post-deployment cohort analysis. Additionally, all potential recruits were informed that PFT results would remain confidential, but it is possible that select soldiers with ongoing respiratory problems may have declined participation for fear it might damage their careers. Finally, our study relied nearly completely on self-reporting symptoms and conditions. Most of those reporting a history of asthma did not have an asthma diagnosis in the chart, but as noted above, those with the reported history were more likely to have abnormal PFTs. This strengthens the reliability of the self-reporting in this study.

\section{Conclusions}

In this study, a basic pre-deployment pulmonary evaluation of military personnel, including spirometry and a respiratory symptoms survey, was revealing of the overall fitness of the deploying force. Notable findings include the frequency of undiagnosed asthma and respiratory symptoms before deployment and the predictive nature of increased physical fitness run times for potentially underlying disease. The combination of spirometry along with specific questions about asthma history, wheezing, exercise intolerance, and 2-mile run times may identify individuals at the highest risk for increased respiratory symptoms during deployment to austere regions of the world.

\section{REFERENCES}

1. Morris MJ, Rawlins FA, Forbes DA, Skabelund AJ, Lucero PF. Deployment-related respiratory issues. US Army Med Dep J 2016; Apr-Sep(2-16):173-178.

2. Weese CB, Abraham JH. Potential health implications associated with particulate matter exposure in deployed settings in southwest Asia. Inhal Toxicol 2009;21(4):291-296.

3. Morris MJ, Dodson DW, Lucero PF, Haislip GD, Gallup RA, Nicholson KL, Zacher LL. Study of active duty military for pulmonary disease related to environmental deployment exposures (STAMPEDE). Am J Respir Crit Care Med 2014;190(1):77-84.

4. Szema AM, Peters MC, Weissinger KM, Gagliano CA, Chen JJ. New-onset asthma among soldiers serving in Iraq and Afghanistan. Allergy Asthma Proc 2010;31(5):67-71.

5. DelVecchio SP, Collen JF, Zacher LL, Morris MJ. The impact of combat deployment on asthma diagnosis and severity. J Asthma 2015;52(4):363-369.

6. Armed Forces Health Surveillance Center, Naval Health Research Center, United States Army Public Health Command (Provisional) . Epidemiological studies of health outcomes among troops deployed to burn pit sites. Silver Spring, Maryland: Armed Forces Health Surveillance Center; 2010. https://www.vetshq.com/wp-content/ 


\section{Pulmonary Function in Military Personnel}

blogs.dir/files/sites/11/2013/10/Epidemiological-Studies-of-HealthOutcomes-Among-Troops-Deployed-to-Burn-Pit-Sites.pdf. Accessed March 29, 2017.

7. Institute of Medicine. Long-term health consequences of exposure to burn pits in Iraq and Afghanistan. Washington, DC: The National Academies Press; 2011.

8. Petruccelli BP, Goldenbaum M, Scott B, Lachiver R, Kanjarpane D, Elliott E, et al. Health effects of the 1991 Kuwait oil fires: a survey of US army troops. J Occup Environ Med 1999;41(6):433-439.

9. Lange JL, Schwartz DA, Doebbeling BN, Heller JM, Thorne PS. Exposures to the Kuwait oil fires and their association with asthma and bronchitis among Gulf War veterans. Environ Health Perspect 2002;110(11):1141-1146.

10. Sanders JW, Putnam SD, Frankart C, Frenck RW, Monteville MR, Riddle MS, et al. Impact of illness and non-combat injury during Operations Iraqi Freedom and Enduring Freedom (Afghanistan). Am J Trop Med Hyg 2005;73(4):713-719.

11. Smith B, Wong CA, Smith TC, Boyko EJ, Gackstetter GD, Ryan MAK. Newly reported respiratory symptoms and conditions among military personnel deployed to Iraq and Afghanistan: a prospective population-based study. Am J Epidemiol 2009;170(11):1433-1442.

12. Rose CS. Military service and lung disease. Clin Chest Med 2012; 33(4):705-714.

13. Szema AM. Occupational lung diseases among soldiers deployed to Iraq and Afghanistan. Occup Med Health Aff 2013. doi: 10.4172/ 2329-6879.1000117.

14. King MS, Eisenberg R, Newman JH, Tolle JJ, Harrell FE Jr, Nian H, et al. Constrictive bronchiolitis in soldiers returning from Iraq and Afghanistan. N Engl J Med 2011;365(3):222-230.

15. Roop SA, Niven AS, Calvin BE, Bader J, Zacher LL. The prevalence and impact of respiratory symptoms in asthmatics and non-asthmatics during deployment. Mil Med 2007;172(12):1264-1269.

16. Rose C, Abraham J, Harkins D, Miller R, Morris M, Zacher L, et al. Overview and recommendations for medical screening and diagnostic evaluation for post-deployment lung disease in returning US warfighters. J Occup Environ Med 2012;54(6):746-751.

17. Zacher LL, Browning R, Bisnett T, Bennion JR, Postlewaite RC, Baird CP. Clarifications from representatives of the Department of
Defense regarding the article "Recommendations for medical screening and diagnostic evaluation for postdeployment lung disease in returning US warfighters." J Occup Environ Med 2012;54(6):760761.

18. Hankinson JL, Odencrantz JR, Fedan KB. Spirometric reference values from a sample of the general U. S. population. Am J Respir Crit Care Med 1999;159(1):179-187.

19. Cochet AA, Lucero PF, Zacher LL, Morris MJ. Prevalence of supranormal pulmonary function testing values between a military and non-military cohort. Respir Care 2014;59(5):749-755.

20. Karlinsky JB, Blanchard M, Alpern R, Eisen SA, Kang H, Murphy FM, Reda DJ. Late prevalence of respiratory symptoms and pulmonary function abnormalities in Gulf War I veterans. Arch Intern Med 2004;164(22):2488-2491.

21. Abraham JH, Baird CB. A case-crossover study of ambient particulate matter and cardiovascular and respiratory medical encounters among U. S. military personnel deployed to Southwest Asia. J Occup Environ Med 2012;54(6):733-739.

22. Abraham JH, Clark LL, Sharkey JM, Baird CP. Trends in rates of chronic obstructive respiratory conditions among US military personnel, 2001-2013. US Army Med Dep J 2014;Jul-Sep:33-43.

23. Falvo MJ, Abraham JH, Osinubi OY, Klein JC, Sotolongo AM, Ndirangu D, et al. Bronchodilator responsiveness and airflow limitation are associated with deployment length and Iraq and Afghanistan veterans. J Occup Environ Med 2016;58(4):325-328.

24. Morris MJ, Grbach VX, Deal LE, Boyd SY, Morgan JA, Johnson JE. Evaluation of exertional dyspnea in the active duty patient: the diagnostic approach and the utility of clinical testing. Mil Med 2002; 167(4):281-288.

25. Morris MJ, Eschenbacher W. Chapter 9. Discussion summary: Recommendation for surveillance spirometry in military personnel. In: Baird CP, Harkins DK, editors. Airborne hazards related to deployment. Fort Sam Houston, Texas: Office of the Surgeon General, Borden Institute; 2015:95-102.

26. Townsend MC. ACOEM position statement: spirometry in the occupational setting: American College of Occupational and Environmental Medicine. J Occup Environ Med 2000;42(3):228-245.

This article is approved for Continuing Respiratory Care Education credit. For information and to obtain your $\mathrm{CRCE}$

(free to AARC members) visit www.rcjournal.com 